\title{
THE EFFECT OF DIETARY VITAMIN C ON CARBOHYDRATE CONCENTRATIONS AND HYDROLASE ACTIVITY, DURING THE DEVELOPMENT OF HONEY BEE WORKER BROOD
}

\author{
Marek Farjan ${ }^{1}$ \\ Krystyna Żółtowska ${ }^{1}$ \\ Zbigniew Lipiński \\ Elżbieta Łopieńska-Biernat ${ }^{1}$ \\ Małgorzata Dmitryjuk ${ }^{1 \star}$
}

\author{
'University of Warmia and Mazury, Faculty of Biology and Biotechnology, \\ Department of Biochemistry, Oczapowski 1A, 10-957 Olsztyn, Poland \\ 2Institute of Animal Reproduction and Food Research, \\ The Polish Academy of Sciences, Bydgoska 1/8, 10-243 Olsztyn, Poland \\ *corresponding author: m.dmit@uwm.edu.pl \\ Received 22 November 2013; accepted 18 December 2014
}

\begin{abstract}
The colony collapse disorder is a growing problem world-wide. For this reason, we were prompted to search for natural and harmless agents that could improve the living conditions of honey bees. This group of agents includes exogenous antioxidants, such as ascorbic acid, which boost natural immunity. We analysed the effect of vitamin C supplementation on carbohydrate metabolism in the developing honey bee worker brood. The total carbohydrate content and the concentrations of glycogen, trehalose, maltotriose, fructose, and glucose were estimated. The correlations between sugar content and the activity of the main hydrolases of carbohydrate metabolism - $\alpha$-amylase, glucoamylase, trehalase, maltase, and sucrase - were determined. The addition of vitamin $C$ to the diet of wintering bees did not impair their sugar metabolism. Vitamin $\mathrm{C}$ supplements exerted a positive effect by significantly increasing glycogen and trehalose concentrations in the initial phase of development and in newly emerged workers. Vitamin C did not induce significant changes in the developmental profile of carbohydrate degrading enzymes, except for the earliest stage of larval development when enzyme activity levels were below those noted in the control group.
\end{abstract}

Keywords: $\alpha$-glycosidases, Apis mellifera carnica, carbohydrates, vitamin C, worker brood.

\section{INTRODUCTION}

Every winter, significant losses are reported in bee colonies around the world (Van Engelsdorp et al., 2009). There is a call for effective strategies that would keep bee colonies in good health. This study evaluates the effect of vitamin C (ascorbic acid, $A A)$ used to boost natural immunity. Ascorbic acid has antioxidant properties, and it participates in immune responses (Maellaro et al., 1996; Campbell et al., 1999). The role played by vitamin $C$ in insects remains unknown, but its deficiency is commonly associated with abnormalities in cuticular sclerotisation (Kramer and Seib, 1982).
It is believed that vitamin C is not an essential nutrient for bees, but further research is needed to substantiate this assumption. Due to lack of knowledge about ascorbic acid requirements in bees, high doses of vitamin $\mathrm{C}$ are sometimes recommended, especially in artificial diets (Black, 2006). Ascorbic acid is a relatively cheap and safe diet supplement (Harz et al., 2010). Vitamin C is naturally present in the food of bees. Nectar and pollen are rich in proteins, lipids, antioxidants, microelements, and vitamins, including vitamin $C$. The ascorbic acid content of pollen is estimated at $152-640 \mu$ per gram of pollen, depending on the source. The AA concentrations vary subject to the time of collection (Roulston and Cane, 2000). Loper et al. (1980) have 
shown that ascorbic acid concentrations in bee bread decreased from $20.6 \mathrm{mg} / 100 \mathrm{~g}$ to $5.9 \mathrm{mg} / 100 \mathrm{~g}$ after 7 days of storage as a result of fermentation processes. Their results support the use of vitamin C supplements, in particular in wintering bees whose physiology differs from that of summer bees (Münch et al., 2008).

The amount of vitamin $C$ in the diet has been found to be correlated with the size of mature bee broods (Herbert et al., 1985). Excessive intake of vitamin C has no adverse effects on bee health, whereas an $A A$ deficiency can cause underdevelopment of the hypopharyngeal glands, which leads to an inadequate composition of royal jelly produced by the nurse bees (Herbert, 1992). Interestingly, variations in dietary levels of vitamin $C$ had no influence on the final concentrations of ascorbic acid in bees (Herbert et al., 1985). This observation could suggest that bees and their symbiotic partners are capable of synthesising vitamin $\mathrm{C}$. The results of our previous study also indicate that $A A$ could be synthesised by honey bee pupae or by their gut microbiota (Farjan et al., 2012). The second hypothesis is more probable because many insects are deprived of L-gulono- $\gamma$-lactone oxidase, the enzyme involved in the final stages of biosynthesis of L-ascorbic acid in animals (Kramer and Seib, 1982). The activity of the above enzyme was not detected in honey bees, either (Zaobidna, unpubl. data). It should also be noted, that a vitamin $\mathrm{C}$ supplement to the diets of wintering honey bees stimulated their antioxidant defence system. As a result, the losses sustained in colonies of wintering bees were $33 \%$ lower in groups receiving $A A$ than in bees whose diets were not supplemented with vitamin C (Farjan et al., 2012). Supplementing wintering bees' diets with ascorbic acid not only stimulated their antioxidant defence, but also increased their immunity to Varroa destructor (Farjan et al., 2014).

Ascorbic acid has not been found to bring about harmful effects. An evaluation of the influence of vitamin C on carbohydrate metabolism in winter bees could produce interesting results. Saccharides are the major source of energy for bees. Sugar metabolism seems to be an important process in honey bees because their diet is very rich in carbohydrates. This observation is supported by the fact that honey bee genome contains 174 genes responsible for carbohydrate metabolism, but only 28 genes responsible for lipid metabolism (Kunieda et al., 2006). Healthy carbohydrate, protein, lipid, vitamin, and mineral levels in bee diets increase the size of the brood, extend the life span of adult bees, and promote the survival and productivity of the entire colony. Nectar and honey dew are the natural sources of carbohydrates for honey bees (Brodschneider and Crailsheim, 2010).

We were unable to find any studies evaluating the effect of vitamin C supplements on energy metabolism in bees. In this paper, the influence of ascorbic acid on metabolic processes was investigated. A comparison was done of the levels of major carbohydrates (glycogen, trehalose, saccharose, glucose, and fructose) and the activity of enzymes (amylases and disaccharidases) responsible for sugar hydrolysis in worker broods of honey bees whose diets were supplemented with vitamin $C$ in winter and early spring. Our results complement the findings of Farjan et al. $(2012,2014)$ who evaluated the effects of vitamin $C$ on the health of wintering bees.

\section{MATERIAL AND METHODS}

The design of the field experiment was similar to that described by Farjan et al. (2012 and 2014). Eight Apis mellifera carnica colonies headed by sister queens were kept in an apiary near the city of Olsztyn, Poland. Four of the eight colonies (group AA) were fed sugar-water (3:1) syrup, supplemented with ascorbic acid (in a vitamin C formula from Biofactor; Poland,) at $1.8 \mathrm{~g}$ per $1 \mathrm{~kg}$ of syrup. The remaining four colonies (the controls) received pure syrup (group C). Feeding began in September 2007 to enable bees to hoard winter stores (13 litres per colony). The second feeding took place on 1 March 2008. Honeycomb sections were collected from all the colonies on 10 May 2008. The honeycomb sections were divided based on morphological features characteristic of the different stages of development (Jay, 1962; 1963). Similarly to Farjan et al. (2012), we identified 12 developmental stages: 1- to 2-day-old larvae (L1/2), 3-day-old larvae (L3), 4-day-old larvae (L4), 6-day-old larvae (L6), cocoonspinning larvae (L7), prepupae (PP), pupae with white eyes (P1), pupae with pale-pink eyes (P2), pupae with pink eyes (P3), pupae with brown eyes and yellow thorax (P4), and pupae with black eyes and dark thorax (P5). Freshly emerged workers (A) were also examined. The isolated brood was rinsed in $0.9 \%$ $\mathrm{NaCl}$, carefully dried on filter paper and weighed. Fifteen samples representing the examined developmental stages were collected from each colony. Each sample contained 3 individuals representing a given developmental stage, except for stages $L 1 / 2$, $L 3$, and $L 4$, which were represented by samples of 
30, 20, and 10 larvae, respectively. The study was conducted on a total of 180 individuals representing stages $L 6$ to $A$, and on 1800, 1200, and 600 larvae representing stages $L 1 / 2, L 3$, and $L 4$, respectively, from group $C$ or group $A A$. The material was stored at $-70^{\circ} \mathrm{C}$ until further analyses.

Directly before the analysis, brood samples were homogenised in $0.9 \% \mathrm{NaCl}$ at $0.1 \mathrm{~g}$ wet weight per $1 \mathrm{~mL}$ of the solution during $2 \mathrm{~min}$, at $5000 \mathrm{rpm}$, in an ice bath. The homogenate was centrifuged for 10 min at $15000 \times g$, at $4^{\circ} \mathrm{C}$. Supernatant from below the fatty layer was collected for analysis. Before the assay, the extract was diluted 5 times with $0.9 \%$ $\mathrm{NaCl}$.

The total content of sugars was determined by the anthrone method (Morse, 1947). Glycogen content was measured by the method proposed by Sölling and Esmann (1975) with the use of amyloglucosidase derived from Rhizopus (Sigma-Aldrich, Germany/USA). Glucose released during hydrolysis was determined in the Liquick Cormay-Glucose kit for enzymatic determination of glucose (Cormay, Poland). The contents of fructose, trehalose, maltotriose, and saccharose were determined by HPLC. The protocols for sample preparation and analysis were based on the procedures described by Dmitryjuk et al. (2009). Before HPLC, extracts were boiled for $5 \mathrm{~min}$, two volumes of ethanol were added, and the probes were centrifuged after $15 \mathrm{~min}$. Supernatants were desiccated at $50^{\circ} \mathrm{C}$, dissolved in a mixture of acetonitrile/deionised and degassed water (3:2, v/v), and filtered using nylon Micro-Spin Filter Tubes (Alltech Associates, USA). Twenty $\mu$ of each sample was injected into the Shimadzu SCL-10A system with the RID 10A refractive index detector (Kyoto, Japan). A High-Performance Carbohydrate cartridge column (4.6 × $250 \mathrm{~mm}$; Waters, Netherlands) was kept at $35^{\circ} \mathrm{C}$, and it was eluted with a mixture of acetonitrile/deionised and degassed water (75/25\%) at $1 \mathrm{~mL} / \mathrm{min}$. Sugar concentrations were analysed using Chromax 2005 software (POL-LAB; Warsaw, Poland). The results were expressed in $\mathrm{mg}$ of sugar per $100 \mathrm{mg}$ of wet weight. An example of the chromatographic separation trials are shown in Fig. 1.

The activity of $\alpha$-amylase was determined in accordance with the method described by Caraway (1959). The activity of disaccharidases (trehalase, maltase, and sucrase) was determined by the method proposed by Dahlquist (1968). The activity of $\alpha$-amylase was expressed in $\mathrm{mg}$ of decomposed starch per $1 \mathrm{mg}$ of protein. Glucoamylase activity was determined based on the amount of glucose released from glycogen by the enzyme. The activity of glucoamylase and disaccharidases was expressed in $\mu$ of glucose per $1 \mathrm{mg}$ of protein in $60 \mathrm{~min}$. The amount of glucose synthesised during the enzymatic reaction was determined with the use of the Cormay kit (Poland). Protein content was determined by Bradford's method (Bradford, 1976) with purified bovine serum albumin (Sigma-Aldrich, Germany/USA).

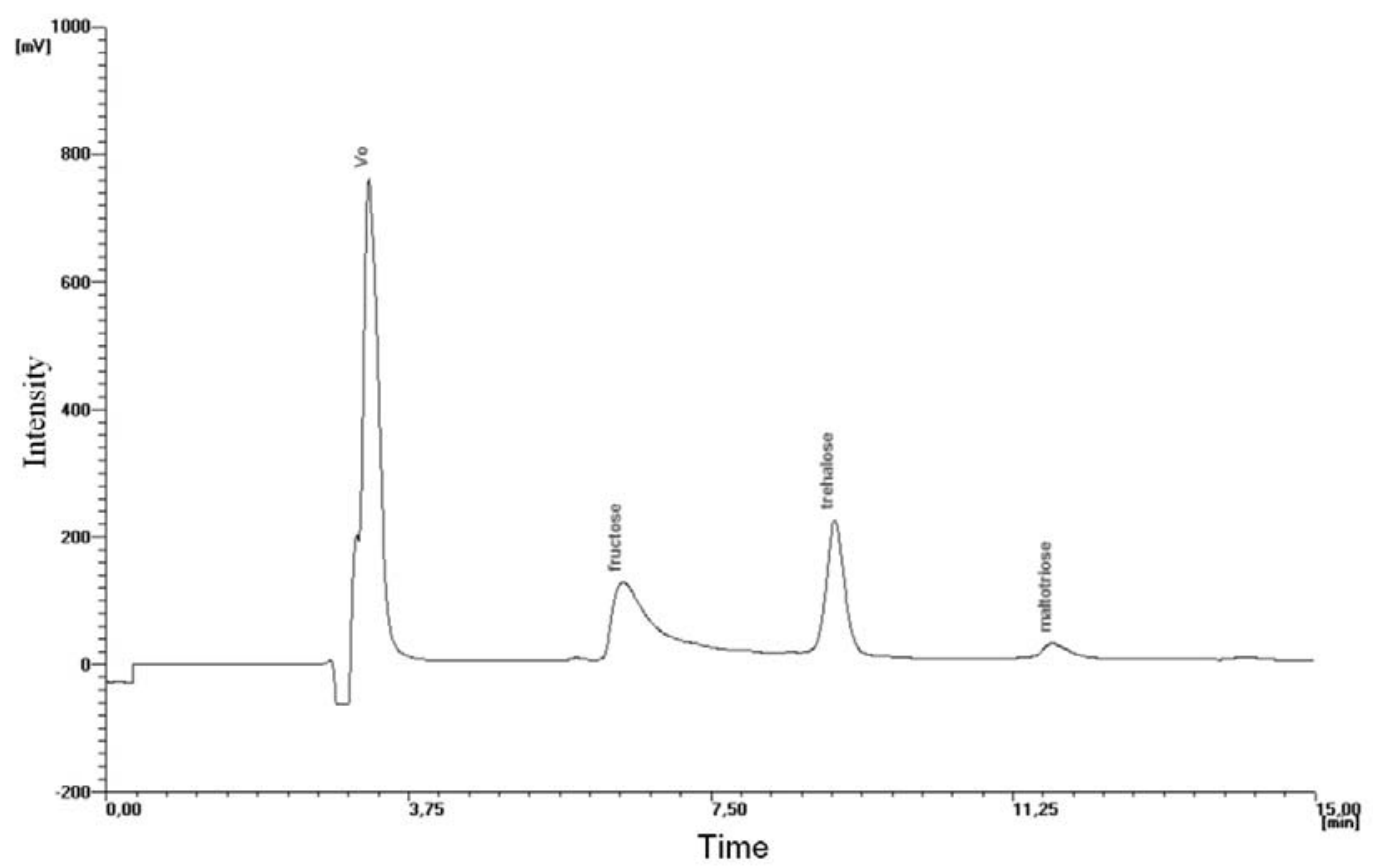

Fig. 1. Sample chromatogram of sugars in L7 worker bees (group C; Vo - initial disorder). 
The results were processed in the Statistica 8 application (StatSoft Inc. Tulsa, Oklahoma, USA). Statistically significant differences at $p<0.05$ were determined with the use of ANOVA and Tukey's test.

\section{RESULTS}

A significant and gradual decrease in sugar content was observed in both groups of developing brood (Fig. 2). Depending on the stage of brood development, vitamin C supplementation induced different changes in total sugar content. In uncapped larval and pupae supplemented with $A A$, sugar concentrations were lower than in the control group. Sugar concentrations in L6-7 larvae, prepupae, and imagines were higher, however, in the group receiving ascorbic acid than in the control. The observed difference was statistically significant in L7 larvae.

In all stages of development, glycogen had the highest share of the sugar pool in both groups, and it ranged from $65.99 \pm 1.30 \%(A)$ to $76.61 \pm$ $5.50 \%$ (L6) in group C, and from $66.59 \pm 2.92 \%$ (A) to $77.33 \pm 12.34 \%$ (L1/2) in group AA (Tab. 1). In newly emerging imagines, glycogen concentrations were lowest during development (Fig. 3). Sugar levels were higher in bees receiving ascorbic acid, except for stage L4 and stage P1-P3 bees. Glycogen levels were nearly twice higher in $L 1 / 2$ bees and nearly $40 \%$ higher in L3 bees from the AA group in comparison with the control. Glycogen concentrations were also significantly higher at the end of metamorphosis in P4-P5-pupae and in newly emerged workers in the AA group than in the control group (Fig. 3).

Trehalose was the second most abundant carbohydrate whose proportion in total sugars ranged from $9.63 \pm 13.21 \%$ (P5) to $16.44 \pm 0.75 \%$ (P4) in group C, and from $9.71 \pm 1.07 \%$ (P5) to $16.28 \pm 0.29 \%$ (L7) in group AA (Tab. 1). During larval development, trehalose content increased and reached its maximum in $\mathrm{L} 6$ or $\mathrm{L} 7$ bees in both groups (Fig. 4). In most cases, trehalose levels were higher in the experimental bees, but significant differences between mean values were noted in the larval stages, except

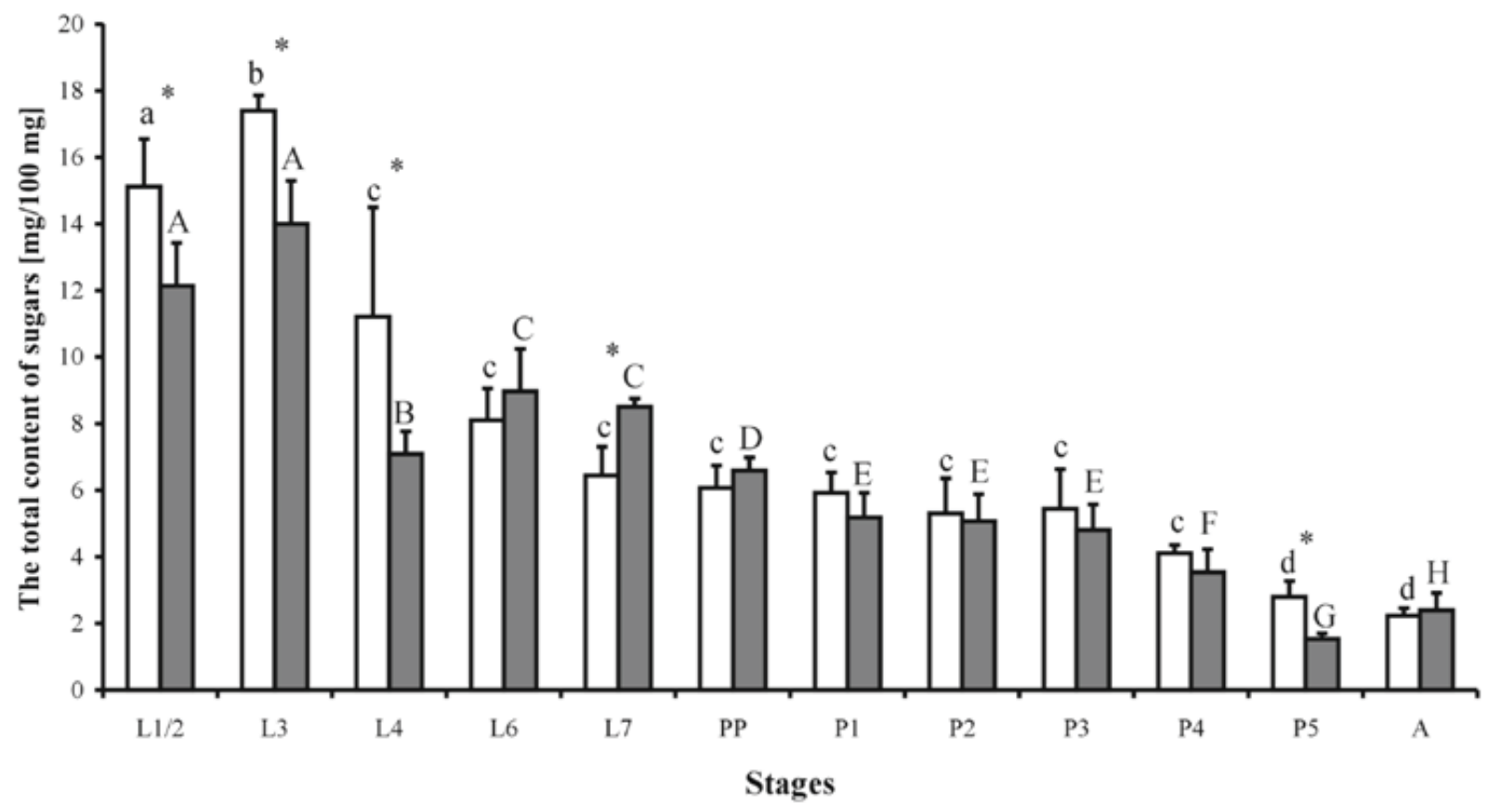

पC - control group $\square \mathrm{AA}$ - ascorbic acid supplementation group

Fig. 2. Total sugar content in developing worker brood of honey bees [mg/100 mg wet weight]. Small letters indicate significant differences between mean values reported in adjacentstages of development in the control group ( $C ; p<0.05)$. Capital letters indicate significant differences between mean values reported in adjacent stages of development between groups after the administration of ascorbic acid ( $A A ; p<0.05)$. * Significant differences in mean values between the control group $(C)$ and the experimental group (AA) in the same stage of development $(p<0.05)$.

L1/2 - 1- to 2-day-old larvae, L3 - 3-day-old larvae, L4 - 4-day-old larvae, L6 - 6-day-old larvae, L7 - cocoonspinning larvae, PP - prepupae, P1 - pupae with white eyes, P2 - pupae with pale-pink eyes, P3 - pupae with pink eyes, P4 - pupae with brown eyes and yellow thorax, P5 - pupae with black eyes and dark thorax, A - freshly emerged workers 
$\frac{\mathscr{\oplus}}{\frac{0}{\sigma}}$

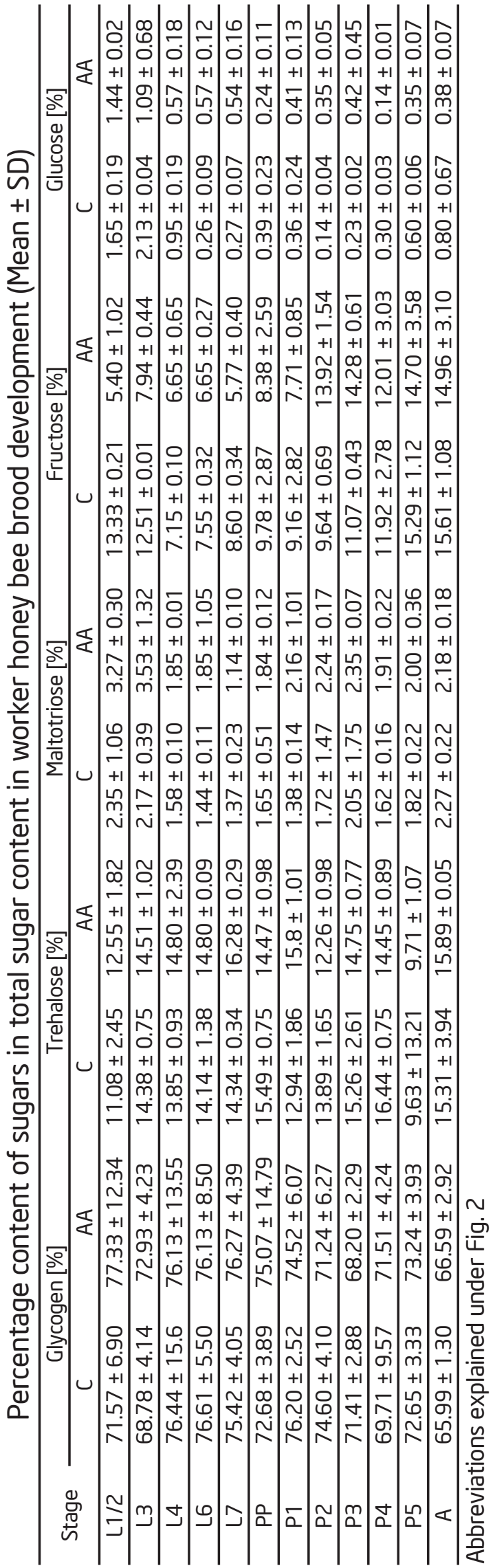

for L4. Significant differences in trehalose concentrations were also reported between the imagines and P5 stage bees (Fig. 4).

The share of maltotriose in the sugar pool ranged from $1.37 \pm 0.23 \%$ (L7) to $2.35 \pm 1.06 \%$ (L1/2) in group $C$, and from $1.14 \pm 0.10 \%$ (L7) to $3.53 \% \pm 1.32$ (L3) in group AA (Tab. 1). The enrichment of honey bee diets with ascorbic acid increased their maltotriose content. In comparison with the control, maltotriose levels in group AA were 2- or 3-fold higher in the initial stages of development, and they were also higher in successive stages, except for L7 (Fig. 5).

Fructose had a very high share of the carbohydrate pool. In selected developmental stages, the fructose content exceeded the trehalose levels. In the final stages of development, fructose had an estimated $15 \%$ share of the sugar pool in both groups (Tab. 1). In comparison with the control, fructose concentrations were lower in group AA up to the P1 stage (Fig. 6), after which fructose levels in the experimental bees increased to more than that determined in the control group. Glucose concentrations were very low - at less than one percent in most cases (Tab. 1). Higher glucose levels were observed in the uncapped larvae of both groups (Fig. 7). A small peak in retention time for saccharose was observed only in selected samples, which is why saccharose data were not presented in this work.

Amylase activity was low in both brood groups (Fig. 8 and 9). Disaccharidases levels remained fairly stable throughout the experiment (Fig. 10-12). Besides amylase, the activity of other hydrolases in the AA group was higher in the youngest larvae, it decreased in 3-day-old larvae, and increased considerably in L4 larvae which were fed a mix of honey and pollen by nurse bees. Enzyme activity levels, excluding maltase, decreased significantly in prepupae relative to the younger stages. Enzyme levels increased during pupation, and a significant increase was noted in the final stages of development, P5 and A (Fig. 8-11). A particularly high increase was observed in sucrase levels (Fig. 12).

The supplementation of bee diets with vitamin C did not exert a significant effect on the activity of glycosidases (Fig. 8-12). The activity of all enzymes was lower in the youngest (L1/2) larvae in group $A A$ than in group $C$. Enzyme levels, excluding $\alpha$-amylase (Fig. 8), increased in the experimental bees up to stage L4 (Fig. 9-12). During pupation in group AA, significant fluctuations in enzyme levels, including a drop to minimum values, were noted. The above was observed in glucoamylase and trehalase in stage P3 (Fig. 9 and 10). 


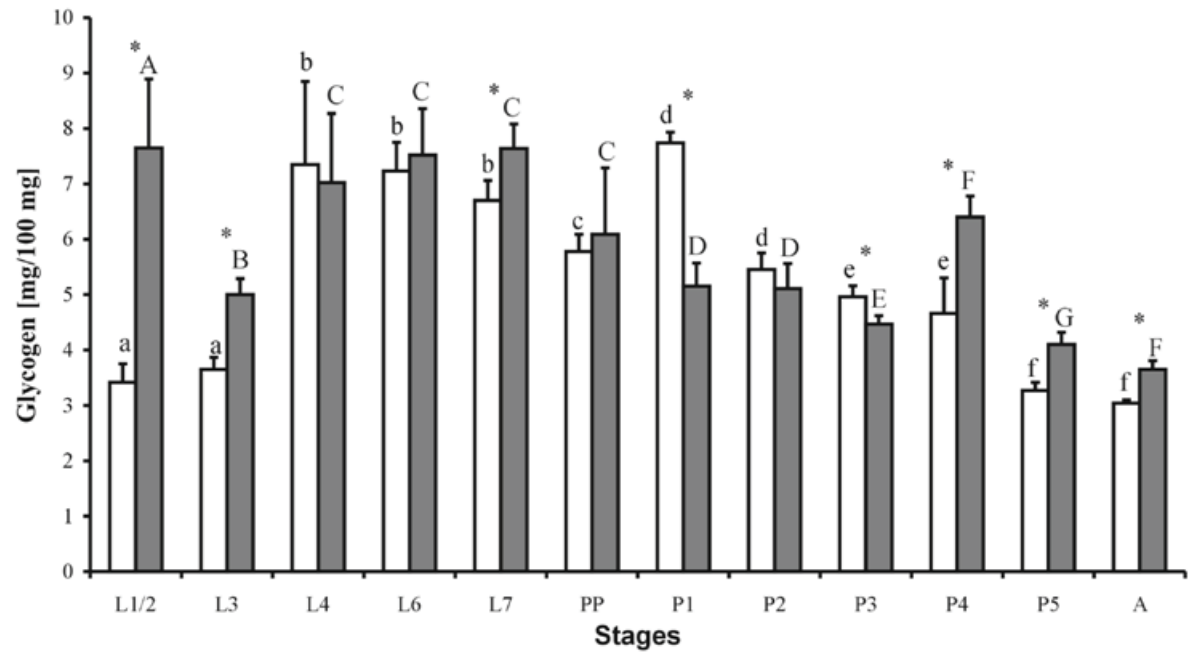

$\square \mathrm{C}$ - control group $\square \mathrm{AA}$ - ascorbic acid supplementation group

Fig. 3. Glycogen content in developing worker brood of honey bees [mg/100 mg wet weight]. Explanation as in Fig. 2.

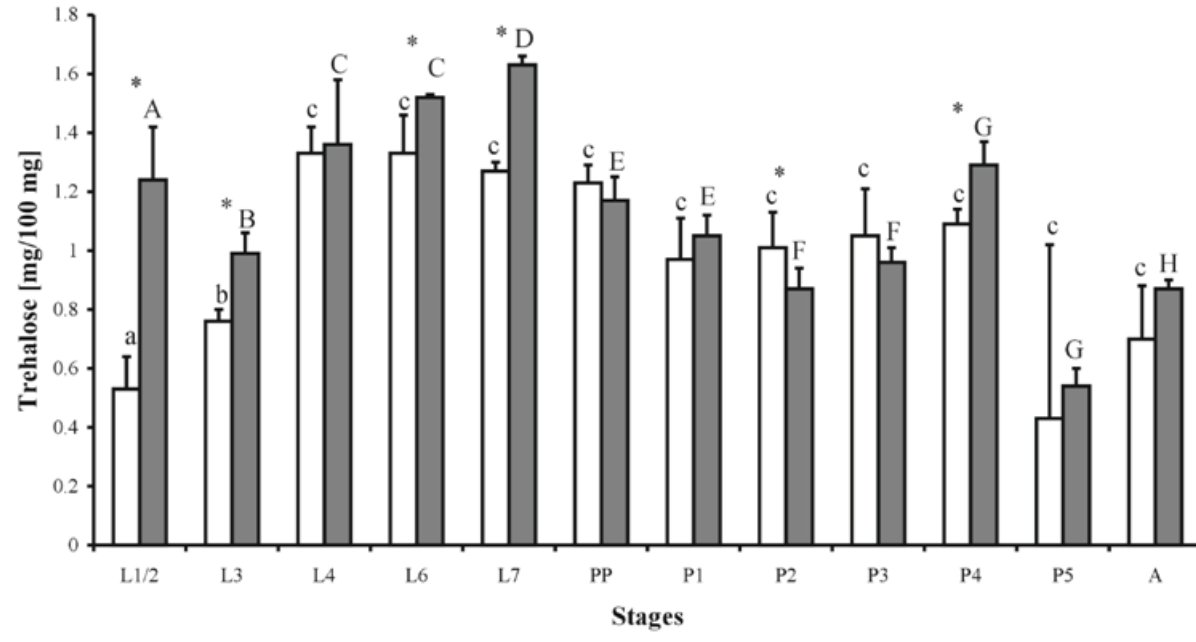

口C - control group $\square \mathrm{AA}$ - ascorbic acid supplementation group

Fig. 4. Trehalose content in developing worker brood of honey bees [mg/100 mg wet weight]. Explanation as in Fig. 2

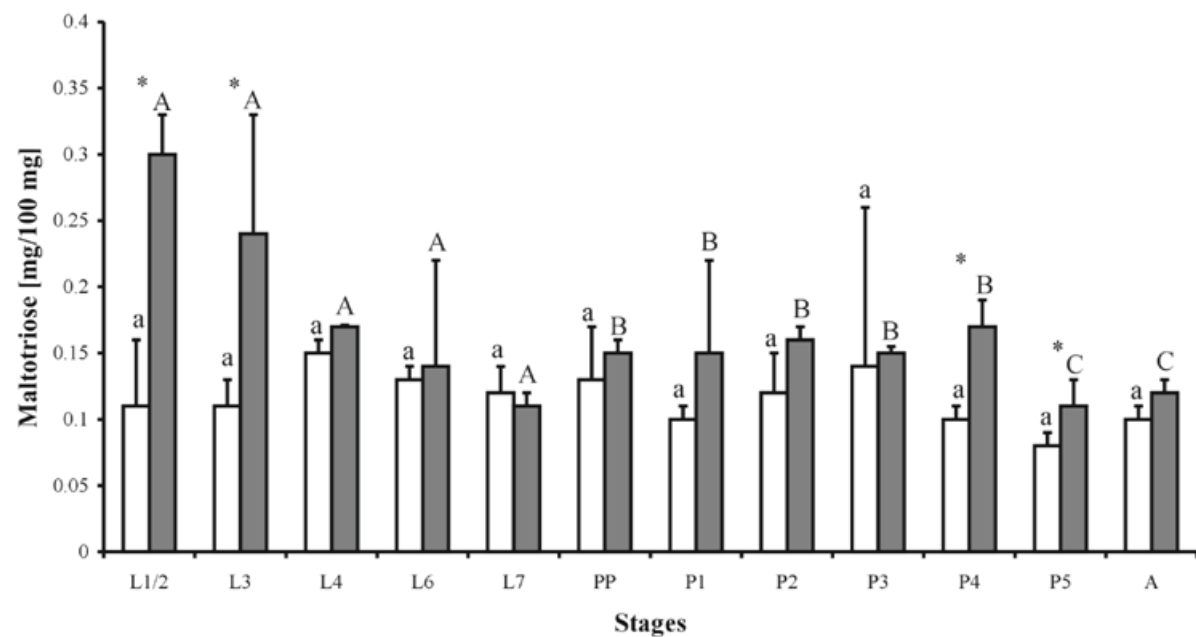

口C - control group $\quad$ AA - ascorbic acid suplementation group

Fig. 5. Maltotriose content in developing worker brood of honey bees [mg/100 mg wet weight]. Explanation as in Fig. 2. 


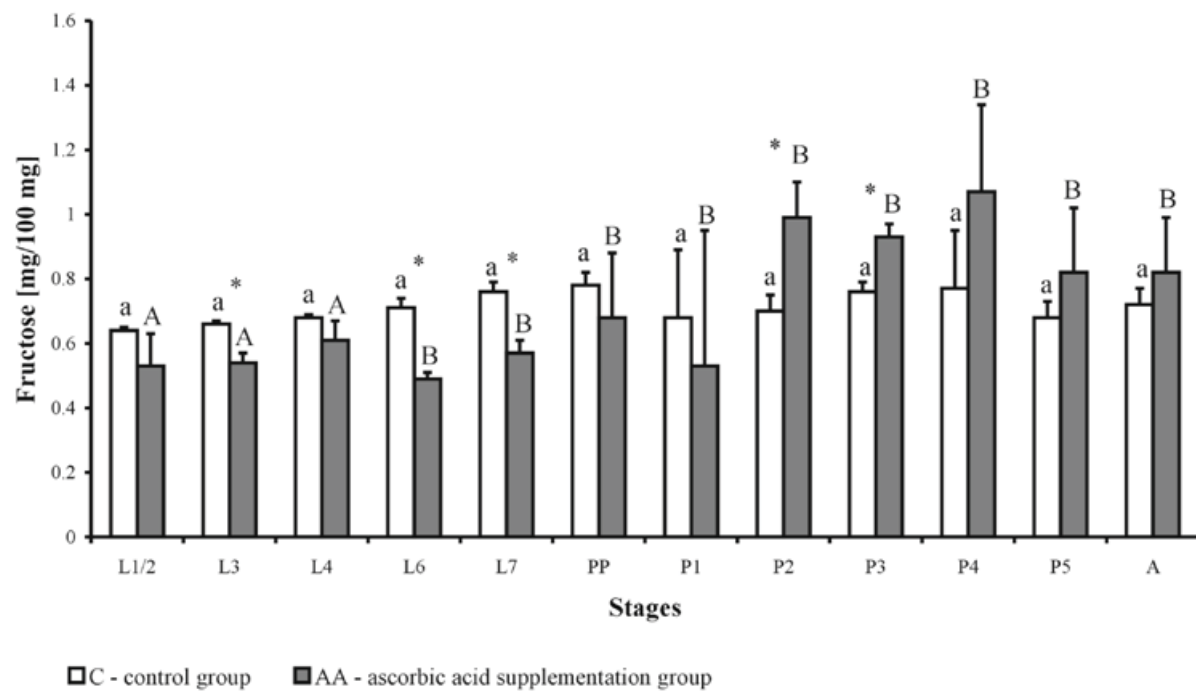

Fig. 6. Fructose content in developing worker brood of honey bees [mg/100 mg wet weight]. Explanation as in Fig. 2.

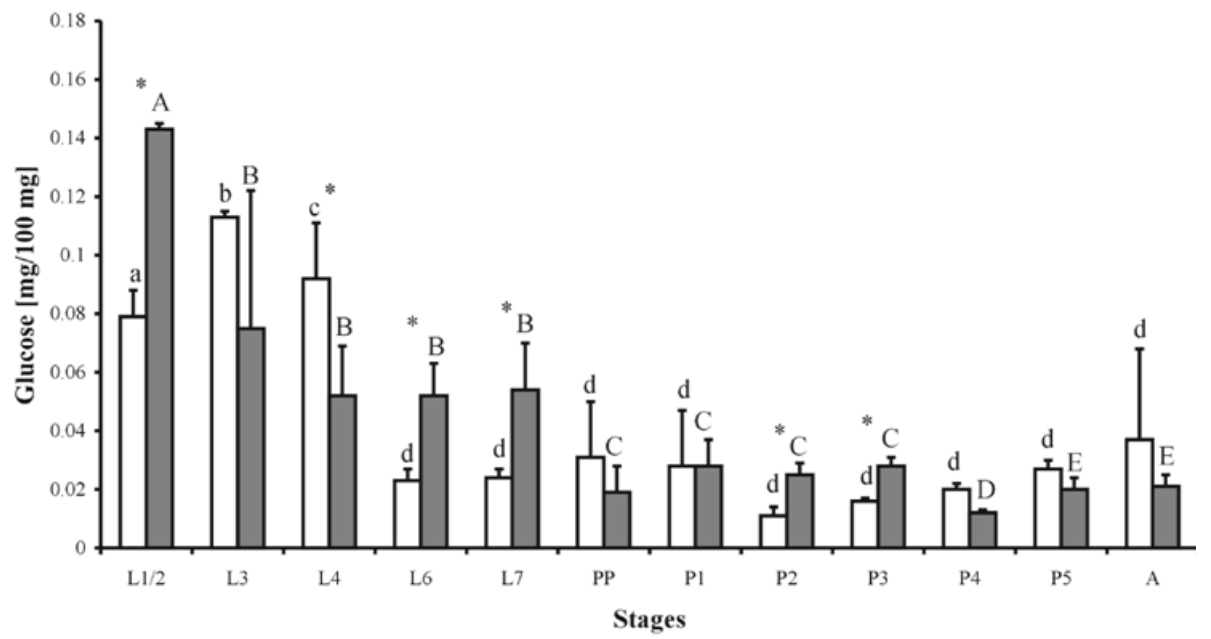

$\square \mathrm{C}$ - control group $\quad \mathrm{AA}$ - ascorbic acid supplementation group

Fig. 7. Glucose content in developing worker brood of honey bees [mg/100 mg wet weight]. Explanation as in Fig. 2.

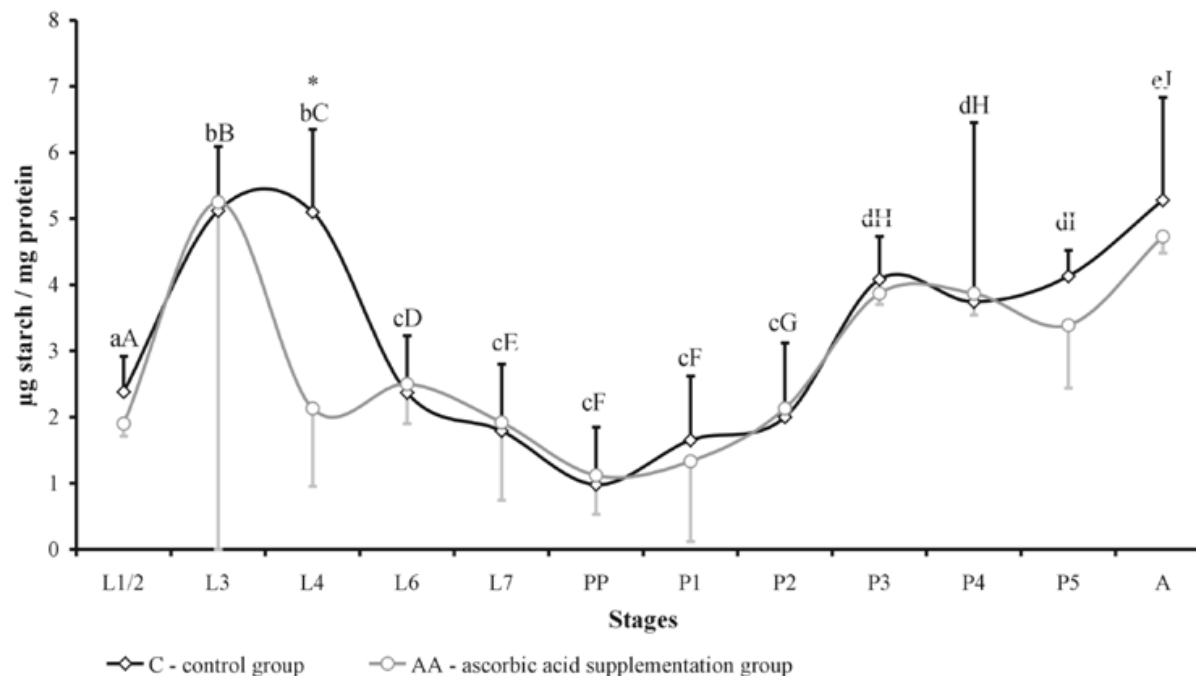

Fig. 8. $\alpha$-amylase activity in developing worker brood of honey bees [ $\mu \mathrm{g}$ starch/mg protein]. Explanation as in Fig. 2. 


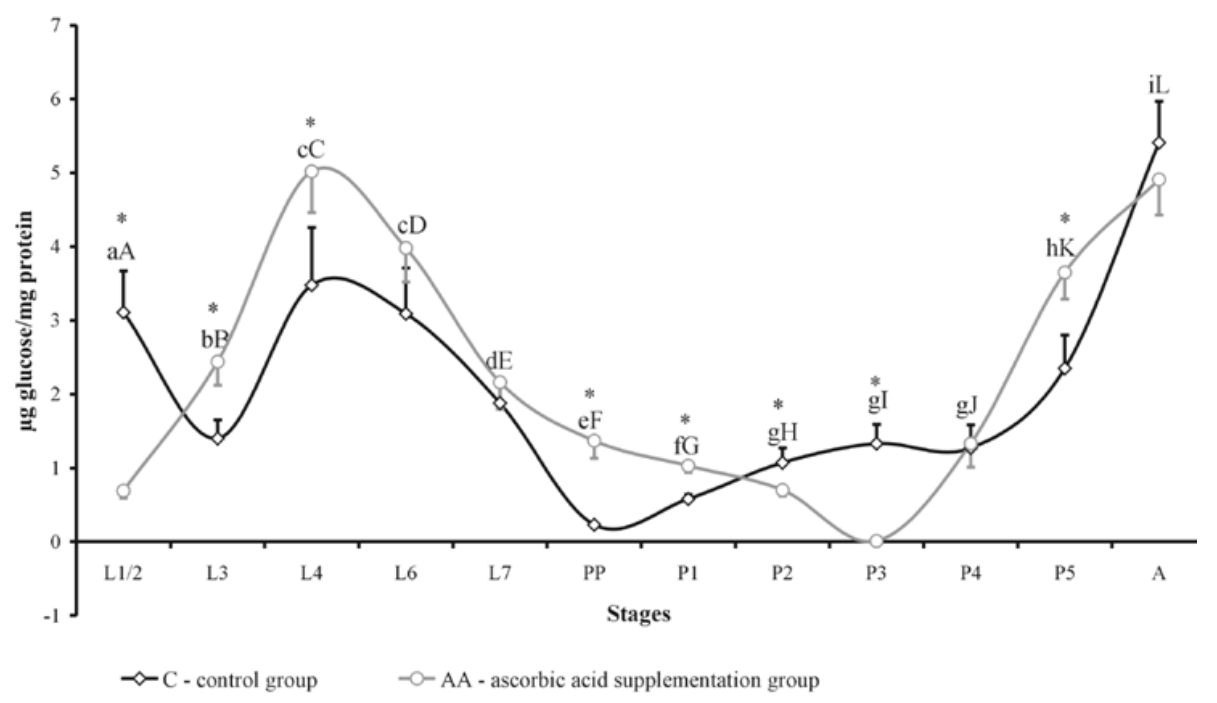

Fig. 9. Glucoamylase activity in developing worker brood of honey bees [ $\mu$ glucose/mg protein]. Explanation as in Fig. 2.

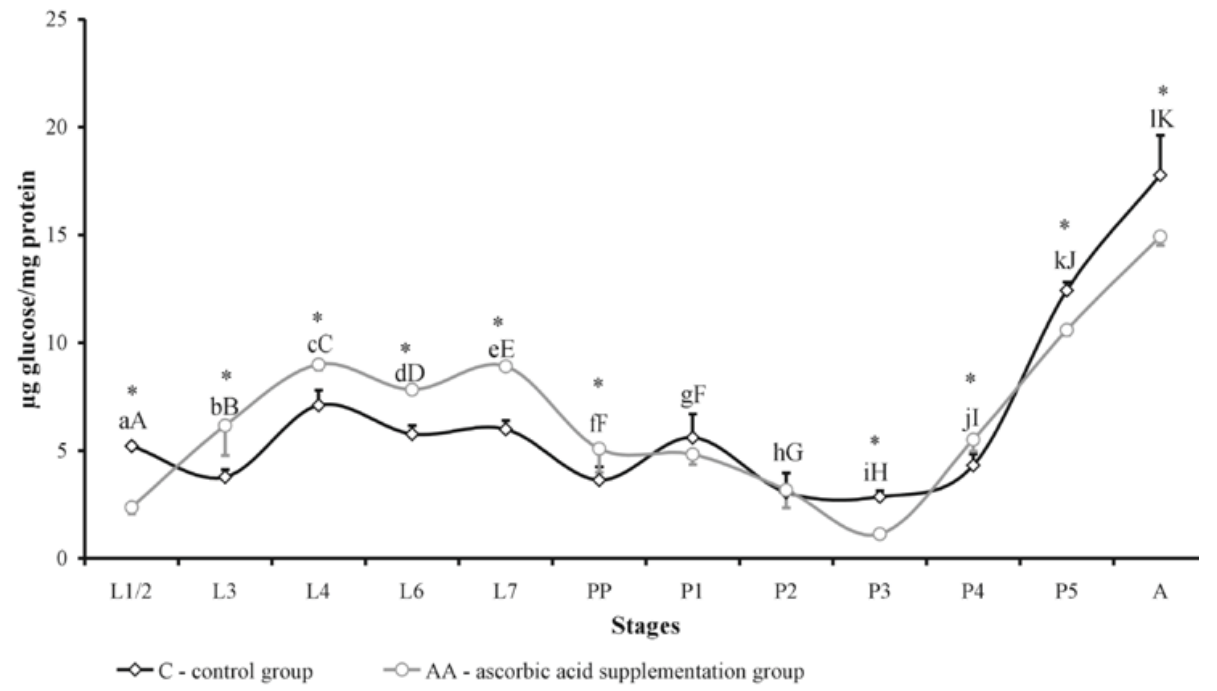

Fig. 10. Trehalase activity in developing worker brood of honey bees [ $\mu \mathrm{g} g$ lucose/mg protein]. Explanation as in Fig. 2.

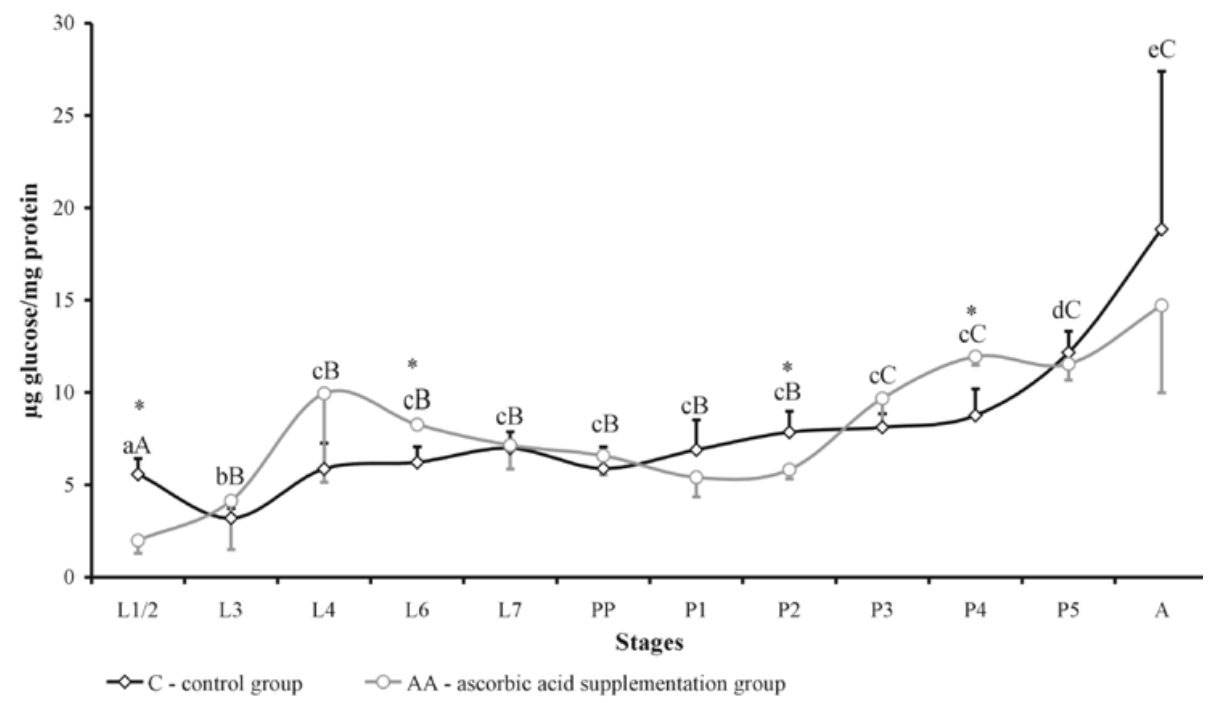

Fig. 11. Maltase activity in developing worker brood of honey bees [ $\mu$ glucose/mg protein]. Explanation as in Fig. 2. 


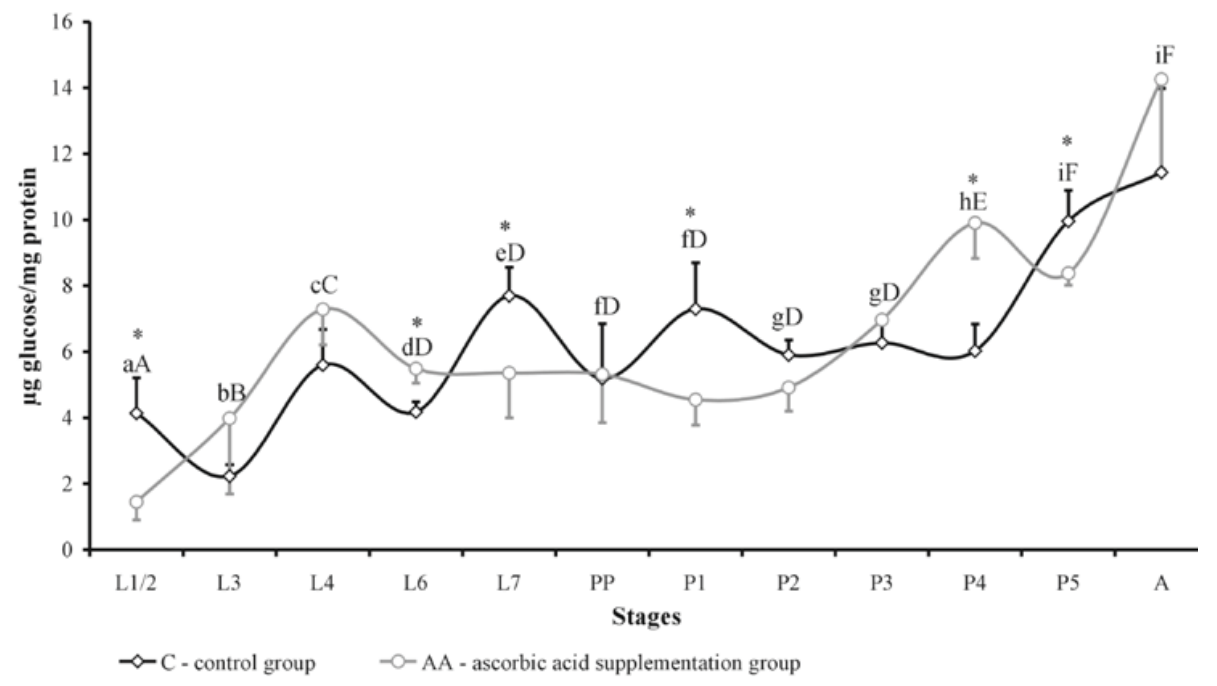

Fig. 12. Sucrase activity in developing worker brood of honey bees [ $\mu \mathrm{g} g$ lucose/mg protein]. Explanation as in Fig. 2.

\section{DISCUSSION}

Our earlier studies demonstrated that supplementation of wintering bees' diets with vitamin $\mathrm{C}$ improved selected physiological and biochemical indicators. The result was lower winter mortality, higher protein, higher TAS and glutathione content, as well as higher activity levels of antioxidant enzymes in emerging worker bees. Ascorbic acid increases resistance to stress factors, and it constitutes a safe, natural and highly available dietary supplement for wintering bees and the spring generation of worker bees (Farjan et al., 2012). The supplementation of bee diets with vitamin $\mathrm{C}$ before winter and in the early spring period could be recommended for colonies infected with $V$. destructor. The reason is that ascorbic acid has been found to reduce the prevalence and intensity of infestations. In a colony affected by varrosis, worker bees that received vitamin $C$ during development were in better condition than bees whose diets were not supplemented with AA (Farjan et al., 2014). The results of this study demonstrated that vitamin $C$ also had a positive influence on carbohydrate metabolism in bees. Ascorbic acid did not lead to a significant increase in total sugar concentrations, but it induced a minor increase in carbohydrate content in newly emerged workers in the AA group. Prepupae from the experimental group were characterised by higher total sugar levels and, consequently, better health. A gradual decrease in carbohydrate concentrations in prepupae from both groups is indicative of a high metabolic rate before pupation. Saccharides are catabolised to provide energy for pupation, and monosaccharides are also involved in the synthesis of new carbohydrates, such as chitin (Draczyński, 2008). Our findings are consistent with the results reported by Bishop (1923) who investigated sugar concentrations in the hemolymph of developing bee brood. Schmolz et al. (2005) also observed a decrease in the carbohydrate content of capped larvae, in particular in spinning larvae and in the oldest pupae. They suggested that sugars were used to rebuild lipids whose content increased during metamorphosis and observed that drones store more lipids than honey bee workers. Their findings point to a greater decrease in sugar concentrations in the final stage of drone development than in workers. A similar observation was made when our results were compared with those reported for drones (Lipiński et al., 2008). In this study, sugar levels in both groups of workers remained fairly stable during pupation, whereas a steep decline was observed in drones. In stages PP and P1, a negative feedback mechanism was observed between trehalose content and glycogen concentrations, which indicates that metabolic processes involving both carbohydrates are closely correlated in invertebrates (Behm, 1997). The increase in trehalose content was almost identical in the control spinning larvae of the control group of workers (to $1.27 \mathrm{mg} / 100 \mathrm{mg}$ ) and drones (to $1.29 \mathrm{mg} / 100 \mathrm{mg}$ ) (Lipiński et al., 2008). In the experimental group, dietary supplementation increased trehalose concentrations in the $L 7$ bees to $1.63 \mathrm{mg} / 100 \mathrm{mg}$.

Vitamin C contributes to the preservation of stable and usually higher glycogen levels in worker larvae. Such a contribution probably takes place at the expense of glucose. Concentrations of glucose in the group receiving vitamin C were almost $50 \%$ lower 
in L3-4 than in the control. It is worth noting, that glycogen levels in the final stages of brood development were significantly higher in the experimental group than in the control (Fig. 3).

Trehalose was the most abundant soluble carbohydrate in the worker brood of honey bees, and trehalose concentrations were higher in group $A A$, except for the PP and P2-3 stages. Similar results were obtained by Blatt and Roces (2001). Maltotriose concentrations were also higher in the supplemented group, excluding L7 larvae. In turn, the high fructose levels in the experimental group of workers were completely surprising. It is particularly noteworthy that fructose concentrations were expected to be lower than glucose levels beginning from the stage that does not support the fast conversion of fructose to glucose. Such correlations were not observed in our study, and further work is needed to explain this phenomenon. Saccharose was detected only in several brood samples, and similar results were reported by Leta et al. (1996). The presence of saccharose was anticipated in at least all larvae fed honey and pollen. The discussed phenomenon could be attributed to the relatively high activity levels of sucrase during the analysed period. Sucrase immediately hydrolyses saccharose to monosaccharides, therefore, sucrose concentrations were decreased below the detection limit of our method.

In the last developmental stage, a significant decrease was observed in the total carbohydrate content, and the lowest sugar levels were noted in newly emerging workers of both groups. These findings could be due to the higher activity of enzymes that hydrolyse sugars in the final stages of bee development. The concentrations of individual sugars, excluding glucose, were higher in the group receiving vitamin $C$ than in the control. However, statistically significant differences were reported only for glycogen. The increase in $\alpha$-glycosidase activity in the final stages of the worker brood development promotes independent feeding in worker bees and prepares them for the role of nurse bees in the colony. Enzymatic adaptation for these functions has been especially well-documented during the development of the hypopharyngeal glands in bee workers (Ohashi et al., 1999). It accelerated carbohydrate degradation and explained the significant decrease in glycogen and trehalose levels in the oldest pupae, in particular in the control group. The activity levels of nearly all $\alpha$-glycosidases in the last pupal stage (P5) were somewhat lower in group AA than in the control, which created favorable conditions for the accumulation of carbohydrates in emerging honey bees. This observation is corroborated by the results of previous studies into the drone brood of $A$. m. carnica where the activity of $\alpha$-glycosidases in developing drone brood was negatively correlated with sugar levels (Źółtowska et al., 2007, 2012; Lipiński et al., 2008).

\section{CONCLUSIONS}

In this study, adding supplements of vitamin C in the diets of winter bees did not lead to significant changes in the activity of carbohydrate hydrolysing enzymes. The only exception was the earliest phase of larval development when enzymatic activity levels were lower in the experimental group than in the control. The observed phenomenon could benefit bees because lower sugar breakdown rates could facilitate carbohydrate storage in larvae, and accumulated sugars could be used for growth and mobility at later periods. In L1/2 larvae from the experimental group, glycogen and trehalose concentrations were 2- to 3-fold higher than in the control. Supplementing the diet of wintering bees with vitamin C boosted sugar metabolism in the youngest larvae and increased the concentrations of two sugars that are most important for bees - glycogen and trehalose - in newly emerged workers.

\section{ACKNOWLEDGEMENTS}

We are grateful to the Polish Ministry of Science and Higher Education for funding this study (grant no. NN 308282933).

\section{REFERENCES}

Behm C. A. (1997) The role of trehalose in physiology of nematodes. International Journal for Parasitology 27 (2): 215-229. DOl: 10.1016/s0020-7519(96)00151-8

Bishop G. H. (1923) Body fluid of the honey bee larvae. The Journal of Biological Chemistry 58 (2): 543-565.

Black J. (2006) Honey bee nutrition. Review of research and practices. A raport for Rural Industries Research and Developmental Corporation. Austrialian Government. RIRDC Publication No 06/052: 66.

Blatt J., Roces F. (2001) Heamolymph sugars level in foraging honey bees (Apis mellifera carnica) dependence of 
metabolic rate and in vivo measurement of maximal rates of trehalose synthesis. Journal of Experimental Biology 204: 2709-2716. Available at: jeb.biologists.org/content/204/15/2709.full.pdf+html

Bradford M. M. (1976) A rapid and sensitive method for quantitation of microgram quantities of protein utilizing the principle of protein-dye-binding. Analytical Biochemistry 72: 248-54. DOl: 10.1016/00032697(76)90527-3

Brodschneider R., Crailsheim K. (2010) Nutrition and health in honey bees. Apidologie 41(3): 278-294. DOl: 10.1051/apido/2010012

Campbell J. D., Cole M., Bunditrutavorn B., Vella A. T. (1999) Ascorbic acid is a potent inhibitor of various forms of T cell apoptosis. Cellular Immunology 194(1): 1-5. DOl: 10.1006/cimm.1999.1485

Caraway W. T. (1959) A stable starch substrate for the determination of amylase in serum and other body fluids. American Journal of Clinical Pathology 32: 97-99.

Dahlquist A. (1968) Assay of intestinal disaccharidases. Analytical Biochemistry 22(1): 99-107. DOl: 10.1016/0003-2697(68)90263-7

Dmitryjuk M., Łopieńska-Biernat E., Farjan M. (2009) The level of sugars and synthesis of trehalose in Ascaris suum tissues. Journal of Helminthology 83: 237-243. DOl: 10.1017/S0022149X08165178

Draczyński Z. (2008) Honey bee corpses as an available source of chitin. Journal of Applied Polymer Science 109(3): 1974-1981. DOl: 10.1002/app.28356

Farjan M., Dmitryjuk M., Lipiński Z., Łopieńska-Biernat E., Zółtowska K. (2012) Supplementation of the honey bee diet with vitamin C: The effect on the antioxidative system of Apis mellifera carnica brood at different stages. Journal of Apicultural Research 51 (3): 263-270. DOl: 10.3896/IBRA.1.51.3.07

Farjan M., Łopieńska-Biernat E., Lipiński Z., Dmitryjuk M., Żółtowska K. (2014) Supplementing with witamin C the diet of honey bees (Apis mellifera carnica) parasitized with Varroa destructor. effects on antioxidative status. Parasitology 141: 770-776. DOI: 10.1017/ S0031182013002126

Harz M., Müller F., Rademacher E. (2010) Organic acids: acute toxicity on Apis mellifera and recovery in the haemolymph. Journal of Apicultural Research 49(1): 95-96. DOl: 10.3896/IBRA.1.49.1.14

Herbert E. W. (1992) Honey bee nutrition. In: Graham J. M. (Ed.) The hive and the honey bee. Dadant \& Sons. Hamilton, IL: 197-233.

Herbert E. W., Vanderslice J. T., Higgs D. J. (1985) Effect of dietary Vitamin C levels on the rate of brood production of free-flying and confined colonies of honey bees. Apidologie 16(4): 385-394.

Jay C. S. (1962) Colour changes in honey bee pupae. Bee World 43: 119-122.

Jay C.S. (1963) The development of honeybees in their cells. Journal of Apicultural Research 2: 117-134.

Kramer K. J., Seib P. A. (1 982) Ascorbic acid and the growth and development of insects. In: Seib P. A., Tolbert B. M. (Eds.) Ascarbic acid: Chemistry, Metabolism, and Uses. Advances in Chemistry Series No. 200. American Chemical Society. Washington D.C: 273-291.

Kunieda T., Fujiuki T., Kucharski R., Foret S., Ament S. A., Toth A. L., Ohashi K., Takeuchi H., Kamikouchi A., Kage E., Morioka M., Beye M., Kubo T., Robinson G. E., Maleszka R. (2006) Carbohydrate metabolism genes and pathways in insects: insights from the honey bee genome. Insect Molecular Biology 15(5): 563-576. DOl: 10.111 1/j.13652583.2006.00677.x

Leta M. A., Gilbert C., Morse R. A. (1996) Levels of haemolymph sugars and body glycogen of honeybees (Apis mellifera L.) from colonies preparing to swarm. Journal of Insect Physiology 42(3): 239-245. DOl: 10.1016/00221910(95)00106-9

Lipiński Z., Zółtowska K., Wawrowska J., Zaleska M. (2008) The concentration of carbohydrates in the body of development all stages of Apis mellifera carnica drone brood. Journal of Apicultural Science 52(1): 5-11.

Loper G. M., Standifer L. N., Thomson M. J., Gilliam M. (1980) Biochemistry and microbiology of bee-collected almond (Prunus dulcius) pollen and bee bread. Apidologie $11(1): 63-73$.

Maellaro E., Bello B. D., Comporti M. (1996) Protection by ascorbate against apoptosis of thymocytes: implications of ascorbate-induced nonlethal oxidative stress and poly (ADP-ribosation). Experimental Cell Research 226(1): 105-1 13. DOl: 10.1006/excr.1996.0208 


\section{_ FARJIAN ET HL. Eeffect of vitamin C on honey bee sugar metabolism}

Morse E. E. (1947) Anthrone in estimating low concentration of sugar. Analytical Chemistry 19912): 10121013. DOl: 10.1021/ac60012a021

Münch D., Amdam G. V., Wolschin F. (2008) Ageing in a eusocial insect: molecular and physiological characteristics of life span plasticity in the honey bee. Functional Ecology 22(3): 407-421. DOl: 10.1111/j.13652435.2008.01419.x

Ohashi K., Natori S., Kubo T. (1999) Expression of amylase and glucose oxidase in the hypopharyngeal gland with an age-dependent role change of the worker honeybee (Apis mellifera L.). European Journal of Biochemistry 265(1): 127-133. DOl: 10.1046/j.14321327.1999.00696.x

Roulston T. H., Cane J. H. (2000) Pollen nutritional content and digestibility for animals. Plant Systematics and Evolution 222(1-4): 187-209.

Schmolz E., Kösece F., Lamprecht I. (2005) Energetics of honeybee development. Isoperibol and combustion calorimetric investigations. Thermochimica Acta 437(1-2): 39-47. DOl: 10.1016/j.tca.2005.06.001
Sölling H., Essman V. (1975) A sensitive method of glycogen determination in the presence of interfering substances utilizing the filter-paper technique. AnaIytical Biochemistry 68: 664-668. DOl: 10.1016/00032697(75)90667-3

Statistica v. 8 (2007) StatSoft Inc.

Van Engelsdorp D., Evans J. D., Saegrman C., Mullin C., Haubruge E., Nguyen B. K., Frazier M., Frazier ]., Cox-Foster D., Chen Y., Underwood R., Tarpy D. R., Pettis J. S. (2009) Collony Collapse Disorder: A descriptive study. PLoS ONE 4: e6481. DOl: 10.1371/journal.pone.0006481

Zółtowska K., Lipiński Z., Farjan M. (2007) Activity of selected hydrolases in oncogeny of drone Apis mellifera carnica. Journal of Apicultural Science 51 (1): 95-100.

Zółtowska K., Lipiński Z., Łopieńska-Biernat E., Farjan M., Dmitryjuk M. (2012) The activity of carbohydrate-degrading enzymes in the development of brood and newly emerged workers and drones of the carniolan honeybee, Apis mellifera carnica. Journal of Insect Science 12 (22): 1-11. DOl: insectscience.org/12.22 